Rev. Hist., N²8, vol. 1, Enero-Junio 2021: 347-372

ISSN 0717-8832

https://doi.org/10.29393/RH28-13DMGC10013

\title{
Las disputas por la memoria en el Morro: guerra, fiestas cívicas y nacionalismo en Arica, 1880-1929*
}

The disputes over memory in the Morro: war, memory, and civic acts in Arica, 18801929

Gabriel Cid Rodríguez ${ }^{* *}$

\section{RESUMEN}

El artículo analiza la implementación y desarrollo de la conmemoración de la batalla de Arica (7 de junio de 1880) en dicha ciudad. Por medio de un análisis temporal amplio y con base a una sistemática revisión de la prensa local, la investigación examina los usos y disputas por la memoria de la Guerra del Pacífico en las comunidades peruanas y chilenas de la ciudad, y los usos nacionalistas que le confirieron a las festividades cívicas. El texto releva tanto el uso ritual de la conmemoración para reivindicar la identidad peruana frente a la ocupación chilena hasta 1908; y luego analiza la hegemonía chilena de la conmemoración hasta 1929, donde la ceremonia tuvo un rol importante dentro de las políticas de nacionalización de la frontera.

Palabras clave: Guerra del Pacífico, Arica, conmemoraciones, nacionalismo, memoria colectiva, fiestas cívicas.

\section{ABSTRACT}

The article analyzes the implementation and development of the commemoration of the Battle of Arica (June 7,1880 ) in said city. Through a broad temporal analysis and based on a systematic review of the local press, the research examines the uses and disputes over the memory of the War of the Pacific in the Peruvian and Chilean communities of the city, and the nationalistic uses that they conferred on civic festivities. The text reveals both the ritual use of commemoration to claim the Peruvian identity against the Chilean occupation until 1908; and then the paper analyzes the Chilean hegemony of the commemoration until 1929, where the ceremony had an important role within the policies of nationalization of the frontier.

Keywords: War of the Pacific - Arica - Commemorations - Nationalism - Collective Memory - Civic Celebrations.

Recibido: febrero 2021

Aceptado: mayo 2021

\footnotetext{
* Este trabajo forma parte del proyecto Fondecyt Regular № 1201399, El imaginario de la "Esparta americana": nacionalismo y memoria colectiva en torno a la Guerra del Pacífico, 1879-1929.

** Doctor en Historia, Universidad del País Vasco. Académico del Instituto de Historia, Universidad San Sebastián, Sede Los Leones, Chile. ORCID: https://orcid.org/0000-0001-7174-8014. Correo electrónico: gabriel.cid@uss.cl.
} 


\section{Introducción}

En junio de 2012 una decena de parlamentarios elevó al Congreso una moción para declarar feriado el 7 de junio en la región de Arica y Parinacota, creada apenas un lustro antes. Las razones esgrimidas por los diputados eran sugerentes, y remitían a la tradición patriótica de rememorar hitos históricos en aras de incentivar la identidad nacional entre la población. Ese estímulo era más relevante en zonas fronterizas, donde "hacer carne la soberanía a través de la conmemoración del acto heroico de nuestros compatriotas, cobra vigencia superior en las condiciones de ciudad limítrofe". La celebración de la toma del morro de Arica era tanto un reconocimiento a quienes "desde la puerta norte hacen Patria", como la oficialización de una fecha con un profundo simbolismo para la localidad, pues había significado "la incorporación al territorio nacional de una región diversa, indómita, pletórica de desafíos". "El asalto y toma del Morro de Arica está en la retina de los chilenos, incorporó el límite norte del territorio nacional, es parte de las glorias de nuestro ejército, y sobre todo es el alma de un puñado de chilenos que vibran en la misión de hacer patria", añadían. Por eso, afirmaban que era "un deseo que abunda en el grito de los Ariqueños" volver feriado esa fecha. La moción fue aprobada y en abril de 2013 el proyecto se convirtió en ley ${ }^{1}$.

La fijación en el calendario cívico local del 7 de junio, sin embargo, no era una novedad, pues desde fines del siglo XIX la efeméride era celebrada por la población ariqueña. Tampoco lo era la noción de que estos rituales conmemorativos cumplían un propósito clave en el afianzamiento del sentimiento de chilenidad de la población fronteriza, ni que era preciso rememorar de manera periódica la gesta bélica que había permitido la incorporación de la ciudad a la soberanía chilena. Este artículo se adentra en esa historia, y se propone reconstruir el primer ciclo conmemorativo de la batalla de Arica entre fines de la Guerra del Pacífico y la firma del Tratado de Lima, en 1929.

La relevancia simbólica de Arica, como límite norte de la nueva configuración espacial del Estado chileno, expandida notablemente tras el conflicto de 1879, fue clave en aquellos años. En efecto, como ha sugerido Sergio González Miranda, en el imaginario sobre el "Norte Grande" forjado tras la guerra, ciudades como Antofagasta, Iquique y Arica devinieron en "geosímbolos" de la nueva territorialidad, especialmente por su condición fronteriza ${ }^{2}$. Dentro de estas, Arica - la "puerta norte" del país - poseía un propio símbolo geográfico que devendría central en su identidad: el Morro. Este fue utilizado de modo metonímico para aludir no solo a la ciudad, sino

1 La historia de la ley 20663 y la argumentación que la sustentó puede consultarse en: http://www.leychile.cl/navegar/scripts/obtienearchivo?id=recursoslegales/10221.3/44052/1/hl20663.pdf.

2 González, Sergio. 2009. "El Norte Grande de Chile: la definición histórica de sus límites, zonas y líneas de fronteras, y la importancia de las ciudades como geosímbolos fronterizos", en Revista de Historia Social y de las Mentalidades, Vol. 13, N², Santiago, pp.9-42. 
también a la batalla librada en sus terrenos aquel 7 de junio de 1880: guerra, valentía, abnegación, sacrificio, frontera y soberanía fueron algunos de los significados asociados al Morro. Para Chile, el Morro era el "Gibraltar del Pacífico", la frontera del "Chile del porvenir", según lo definió Vicuña Mackenna días después de la batalla, en su célebre artículo: “iNo soltéis el Morro!"3. Para la comunidad peruana, en cambio, el Morro era conceptualizado como un "nuevo Gólgota" donde los defensores heroicos de la nación peruana habían ofrendado sacrificialmente su vida, como lo hizo Francisco Bolognesi ${ }^{4}$. Es que, como indicaba el prolífico escritor Emilio Rodríguez Mendoza en una visita al lugar en 1902, el Morro no era "un simple montón de rocas" sino una "tumba sagrada", un sitio solemne cargado de historia y leyendas bélicas que vigilaba imponente a la ciudad de Arica ${ }^{5}$.

Así, por su dimensión simbólica, el Morro de Arica y los imaginarios históricos asociados a este estuvieron en permanente disputa entre 1880 y 1929. Una de las formas en las cuales es posible reconstruir dichas polémicas es justamente situarnos desde la perspectiva de las prácticas conmemorativas asociadas al 7 de junio de 1880. Los rituales cívicos vinculados al recuerdo de hechos históricos permiten entender las disputas por el pasado y los usos y abusos de la historia. En efecto, generalmente asociadas a verdaderas "políticas de memoria", tales prácticas inciden en la formación de las identidades nacionales por medio de la selección e imposición de ciertas lecturas canónicas sobre el pasado nacional, refrendadas periódicamente a través de las ceremonias ${ }^{6}$. La identidad nacional se comprende aquí como "la continua reproducción y reinterpretación del patrón de valores, símbolos, recuerdos, mitos y tradiciones que componen el patrimonio distintivo de las naciones, y las identificaciones de los individuos con ese patrón y esa herencia, así como con sus elementos culturales" ${ }^{7}$. Elementos en la definición tales como la reinterpretación de los componentes de lo que caracterizan la identidad nacional, nos permite aproximarnos a su historicidad, es decir, a sus variaciones a lo largo del tiempo.

Solo un enfoque diacrónico, como el trabajado en este texto, permite indagar en ese proceso de formación, reajustes y disputas en torno a los recuerdos sobre los eventos históricos de la guerra y su impacto en la identidad nacional. Por medio del estudio de estas prácticas conmemorativas se pueden comprender las conflictivas dinámicas del recuerdo del conflicto de 1879 para las comunidades presentes en la zona, cada una de las cuales proporcionaba "representaciones simbólicas" del pasado en tensión con otras ${ }^{8}$. El contenido de ese pasado no

\footnotetext{
${ }^{3}$ Benjamín Vicuña Mackenna, “iNo soltéis el Morro!”, El Mercurio, Valparaíso, 21 de junio de 1880.

4 "La romería del domingo al morro y las baterías", El Morro de Arica, 9 de junio de 1908.

${ }^{5}$ Emilio Rodríguez Mendoza, "Una visita al Morro de Arica”, Pluma y Lápiz, Santiago, 2 de febrero de 1902, pp. 5-7.

${ }^{6}$ Gillis, John. (ed). 1994. Commemorations: The Politics of National Identity, Princeton, Princeton University Press.

7 Smith, Anthony D. 2004. Nacionalismo: teoría, ideología, historia, Madrid, Alianza, p. 33.

8 Confino, Alon. 1997. "Collective Memory and Cultural History: Problems of Method", en The American Historical Review, Vol. 102, N5, Chicago, p. 1391.
} 
fue fijo, sino cambiante, polémico y disputado, porque, vale la pena añadir, un mismo hecho histórico puede ser recordado, utilizado y representado de manera diferente. Pero el mismo proceso de formación de las memorias colectivas involucra la presencia de esquemas narrativos que orienten los relatos del pasado, simplificándolos y depurándolos de versiones alternativas ${ }^{9}$. Este tipo de discursos, presentes en cada una de las ceremonias conmemorativas aquí examinadas, proporcionó un marco contextual en que los recuerdos de la Guerra del Pacífico se volvieron inteligibles para las comunidades locales, reivindicando así valores asociados a la "peruanidad" o "chilenidad". Los significados de estas categorías, especialmente en una zona fronteriza, se caracterizaron por su maleabilidad temporal, redefinición de sus contenidos y ser objetos de disputas y controversias por los diversos actores locales ${ }^{10}$.

Estas disputas por la memoria deben ser entendidas dentro del marco de los procesos de chilenización de la frontera, cuyo análisis ha producido una copiosa y completa bibliografía, que ha examinado distintas aristas del proceso de despliegue de políticas estatales para remarcar su presencia en las zonas ocupadas. La estatalidad en el "Norte Grande", la gestión del territorio y la administración, las controversias diplomáticas en la zona, las querellas religiosas, el rol de las escuelas y las asociaciones civiles, el ascenso del discurso nacionalista, la violencia simbólica y factual de la chilenización, junto a las representaciones del "otro" han sido aspectos sobre los cuales la literatura especializada ha dado cuenta de manera sugerente ${ }^{11}$. Este estudio se

9 Wertsch, James V. 2008. "The narrative organization of collective memory", en Ethos, Vol. 36, № 1, New Jersey, pp. 120-135.

${ }^{10}$ Morong, Germán. 2014. "De la historiografía nacional a la historia de los bordes. Violencia epistémica y emergencia de lo subalterno en el contexto de la chilenización del Norte Grande; siglos XIX-XX", en Díaz, Alberto; Ruz, Rodrigo y Galdames, Luis. (Comp.). 2014. Tiempos violentos. Fragmentos de historia social en Arica, Iquique: Ediciones Universidad de Tarapacá, pp. 19-21.

${ }^{11}$ La bibliografía al respecto es muy extensa para ser referida aquí en detalle. Sin pretensión de exhaustividad, algunos de los trabajos que abordan estos ámbitos y que han nutrido la reflexión aquí presentada son González, Sergio. 2008. La llave y el candado. El conflicto entre Perú y Chile por Tacna y Arica (1883-1929), Santiago, Lom/Universidad de Santiago; González, Sergio. 2004. El dios cautivo. Las Ligas Patrióticas en la chilenización compulsiva de Tarapacá (1910-1922), Santiago, Lom; González, Sergio. 2002. Chilenizando a Tunupa. La escuela pública en el Tarapacá andino 1800-1990, Santiago, DIBAM/ Lom; Skuban, William. 2007. Lines in the Sand. Nationalism and Identity on the Peruvian-Chilean Frontier, Albuquerque, University of New Mexico Press; Galdames, Luis, Ruz, Rodrigo y Díaz, Alfonso. 2018. Imaginarios nacionales de la frontera norte chilena. Revistas magazinescas (1883-1930), Iquique, Universidad de Tarapacá; Díaz, Alberto, Ruz, Rodrigo y Galdames, Luis. comp. 2014. Tiempos violentos. Fragmentos de historia social en Arica, Iquique: Ediciones Universidad de Tarapacá; Pizarro, Elías. 2017. Tránsitos historiográficos. Arica y su hinterland (siglos XVI-XX), Iquique, Ediciones Universidad de Tarapacá; Díaz, Alberto, et. al. 2012. "Nación y ritualidad en el desierto chileno. Representaciones y discursos nacionales en lquique (1900-1930)", en Polis, Vol. 11, N 31, Santiago, pp. 373-389; Valdebenito, Felipe y Lube, Menara. 2014. "Las fronteras de la modernidad. El espacio Tacnoariqueño y la nacionalización del Norte Grande chileno (1883-1929)", en Estudios Ibero-Americanos, Vol. 40, № 2, Porto Alegre, pp. 277-303;

Pizarro, Elías y Soto Lara, José, 2020. "La institución del Estado Chileno en el sur peruano: Tacna y Arica, 1880-1929", en Ayer, Vol. 119, №3, Madrid, pp. 75-107; Aguirre, Claudio y Mondaca, Carlos. 2011. "Estado nacional y comunidad andina. Disciplinamiento y articulación social en Arica, 1880-1929”, en Historia, Vol.44, №1, Santiago, pp. 5-50; Barrios, Marbert. 2006. “Arica y Tacna: Ciudadanía en tiempos de conflicto (1880-1929)", en Diálogo Andino, N²8, 
inscribe y dialoga con este acervo historiográfico, remarcando la relevancia de los rituales conmemorativos como instancias que permitieron socializar de manera periódica los discursos sobre la nación y chilenizar el imaginario sobre la guerra de 1879 y sus legados. Este tema, afortunadamente, ha cobrado relevancia últimamente en la literatura, a propósito de las celebraciones de fiestas patrias y efemérides asociadas a la Guerra del Pacífico en Antofagasta e lquique ${ }^{12}$.

En lo que sigue, se examinan las conmemoraciones del 7 de junio en la ciudad de Arica entre fines del siglo XIX hasta 1929. Por medio de una exhaustiva revisión de la prensa local, además de información administrativa de la provincia, este trabajo reconstruye este problema distinguiendo tres momentos históricos, que señalan diferentes maneras de apropiarse del ritual cívico para fines nacionalistas. En primer lugar, indaga en el establecimiento de la conmemoración al alero de la comunidad peruano-ariqueña y los usos de la memoria de la batalla de Arica para reivindicar su identidad, amenazada por los procesos de chilenización. En segundo lugar, se estudia la apropiación chilena de la festividad en la época del centenario y cómo sus usos rituales significaron una ruptura tanto ceremonial como discursiva en la forma en la que se recordó la efeméride del 7 de junio en la ciudad. Por último, el artículo aborda la profundización de los usos nacionalistas del ritual en durante la década de 1920, como el correlato de la agudización de las tensiones fronterizas de cara a la inminencia del plebiscito que definiría el problema jurisdiccional de Tacna y Arica.

\section{Los usos peruanos de la conmemoración: la "cultura de la resistencia", 1890-1908.}

Un análisis detallado de la prensa de la zona disponible permite constatar que, desde mediados de la década de 1890 , que es cuando poseemos registros sistemáticos, hasta la época del centenario, la conmemoración del 7 de junio en el espacio público ariqueño fue patrimonio de

Arica, pp. 63-80; Figueroa, Carolina y Silva, Benjamín. 2006. “Entre el caos y el olvido. La acción docente en la Provincia de Tarapacá-Chile (1880-1930)", en Cuadernos Interculturales, Vol. 4, №6, Viña del Mar, pp. 37-53; Castro, Luis. 2014. "Imaginarios y chilenización: los agentes fiscales chilenos y su visión del espacio y la población andina de la provincia de Tarapacá, norte de Chile 1880-1918", en Anuario de Estudios Americanos, Vol. 71, № 2, Sevilla, pp. 661-690; Ferreira, Elizabeth y Aranda, Gilberto. 2019. "Ciudad de papel Zig-Zag. Chilenizando la frontera norte, Arica 1910-1930", en Cuadernos de Historia, º50, Santiago, pp. 9-42; González, José. 2010. "La Provincia de Antofagasta. Creación y consolidación de un territorio nuevo en el Estado chileno: 1883-1933", en Revista de Indias, Vol. 70, N 249, Madrid, pp. 345-380.; Aguilera, René. 2017. "La cuestión eclesial de Tacna y Arica: religión, paradiplomacia y frontera (1900-1911)", en Aldea Mundo, N 44, Táchira, pp. 91-70.

$12 \mathrm{Cid}, \mathrm{Gabriel}$. 2013. "Nacionalizando memorias periféricas: conmemoraciones y nacionalismo chileno en las regiones de Antofagasta y Tarapacá, 1879-1910", en História Unisinos, Vol. 17, №3, São Leopoldo, pp. 214-225; Cid, Gabriel. 2015. "De guerras, ritos y conquistas: conmemoraciones bélicas y nacionalismo chileno en el «norte grande», 1879-1910", en Cavieres, Eduardo y Chaupis, José. (eds). La Guerra del Pacífico en perspectiva histórica. Reflexiones y proyecciones en pasado y en presente, Santiago, Universidad de Tarapacá, pp. 185-202; y Mondaca, Carlos; Gajardo, Yeliza y Sánchez, Elizabeth. 2017. "Celebrando las fiestas patrias chilenas entre peruanos. Escuela, nacionalismo y ritos cívicos en la frontera norte de Chile (Arica y Tacna, 1890-1929)", en Revista Dilemas Contemporáneos, Vol. 4, №3, Toluca, pp. 1-24. 
la colectividad peruana. En un escenario de "chilenización conciliadora", para utilizar los términos de Sergio González ${ }^{13}$, la comunidad peruano-ariqueña patrimonializó la conmemoración desde una lógica reivindicativa a sus intereses. Esto era esperable dada su amplia preeminencia demográfica en la zona. En 1885 la población chilena ascendía a 7.446, mientras que los ciudadanos peruanos eran 17.261. En 1900 la diferencia era de hecho más amplia, pues la población chilena había descendido a 1.676. Solo hacía 1917 las cifras parecían empatarse de acuerdo con el censo levantado en la zona: los chilenos eran 5.315, mientras que los peruanos 5.632. El número de bolivianos era de $1.391^{14}$.

En dicho contexto, la sociedad civil peruana pudo desplegar esfuerzos conmemorativos asociados a la batalla de Arica, hito histórico que se insertó ritualmente dentro de lo que William E. Skuban ha llamado "cultura de la resistencia" ante los procesos de chilenización ${ }^{15}$. Desde mediados de la década de 1890 las ceremonias comenzaron a desplegarse en el puerto, aunque de manera tímida. Inicialmente tenían un sentido marcadamente religioso, asociado a las misas de réquiem homenajeando a los soldados peruanos que lucharon el 7 de junio, descollando entre ellos la figura de Francisco Bolognesi ${ }^{16}$. Como recordó el publicista Ismael Roca, el aniversario era luctuoso y solemne: "Cuán triste es para el pueblo ariqueño recordar el 7 de junio", afirmaba. Porque desde aquel día, donde "se sacrificó un puñado de espartanos, nada más que por cumplir con su deber", la ciudad se desarrollaba "bajo la ley del cautiverio; haciéndola vivir sin su propia enseña y sin esperanzas de volver al seno de la patria" ${ }^{17}$.

En los años siguientes, además del homenaje religioso se sumó la práctica ritual más significativa asociada a la comunidad peruano-ariqueña: la romería hacia el Morro. El rol de la Sociedad Peruana de Socorros Mutuos, como organizadora principal de la ceremonia fue crucial, sumado a la participación de la Escuela Santa Rosa y el Colegio Peruano. En el cambio de siglo la procesión al lugar del combate congregó en promedio a unas 500 personas, pero a mediados de la primera década del siglo XX ascendió de manera consistente llegando a congregar, en 1908 , a 2.000 personas $^{18}$.

El sentido de la romería hacia el lugar de los caídos estaba cargado de un fuerte componente simbólico, que permiten entender cómo procesó la comunidad peruana el recuerdo del 7 de junio. Estos rituales estaban enmarcados dentro de la idea de sacrificio por la comunidad

\footnotetext{
${ }^{13}$ González, S. 2008. La llave y el candado, pp. 40-44.

${ }^{14}$ Las primeras cifras las proporciona Skuban, William. 2007. Lines in the Sand, p. 32; las últimas en "Memoria del Gobernador del Departamento de Arica", 1917, en Biblioteca Nacional de Chile, Sala Medina, Archivos Documentales, caja 22, vol. 73, p. 5.

${ }^{15}$ Skuban, William. 2007. Lines in the Sand, p. 177.

16 "Misa", El Morro de Arica, 8 de junio de 1895; y "7 de junio", El Morro de Arica, 6 de junio de 1896.

17 Ismael Roca, "Remember", El Morro de Arica, 8 de junio de 1895.

18 "Romería patriótica. En el morro y en las baterías", El Morro de Arica, 10 de junio de 1903; "7 de junio de 1880", El Morro de Arica, 8 de junio de 1904; "La romería del domingo al morro y las baterías", El Morro de Arica, 9 de junio de 1908.
} 
encarnados en particular por la figura de Francisco Bolognesi, a quien Enrique del Piélago calificó como "el último espartano" ${ }^{19}$. El culto a Bolognesi en el cambio de siglo estaba asociado a la reivindicación del honor militar de quien anteponía la muerte a la rendición y el cumplimiento del deber hasta sus últimas consecuencias, cumpliendo simbólicamente un rol paliativo ante la derrota. La misma derrota, contemplando de cerca sus enseñanzas, podía transmutar en victoria en un ejercicio de redefinición retórica del héroe ${ }^{20}$. Así, no debe sorprender que el proceso de heroificación de Bolognesi en aquellos años se haya extendido de manera considerable también en Perú, especialmente con la inauguración de su monumento en Lima en $1905^{21}$, y la concordancia establecida entre el aniversario de la batalla de Arica y la ceremonia de juramento a la bandera por las tropas peruanas. Por eso, en aquellos días se volvían habituales en la prensa ariqueña la publicación de reseñas históricas, poesías, himnos e incluso retratos del héroe militar. ${ }^{22}$

Así, la conmemoración del 7 de junio por parte de la comunidad peruano-ariqueña homenajeaba la idea del valor sacrificial en defensa de la patria, reivindicaba la peruanidad de sus miembros aún bajo soberanía chilena, insistía en la necesidad de resistencia ante la chilenización del territorio y difundía la confianza de un futuro retorno de las "cautivas" hacia el Perú. Ninguna ceremonia desplegó de manera más nítida estos imaginarios que la realizada en 1908 para la conmemoración de la batalla, en lo que fue la última celebración pública peruana en el período aquí examinado: "El espectáculo que presentaba esa gran masa ciudadana sobre los cerros, vista desde la ciudad, era hermosísimo", afirmaba una crónica local, describiendo a las dos mil personas en romería hacia el Morro. Y añadía: "Ello ha puesto de manifiesto, una vez más, que Arica en su totalidad, casi, es peruana, y que somos una misma alma, un solo pensamiento cuando se trata de dejar bien alto el nombre de nuestra patria". ${ }^{23}$

En la multitudinaria conmemoración, organizada por las asociaciones civiles del puerto, los oradores que tomaron la palabra en el Morro utilizaron el recuerdo de Bolognesi y sus compañeros de armas para reivindicar estos valores. El cura Juan Vitaliano Berroa, un destacado defensor de la comunidad peruana frente al proceso de chilenización ${ }^{24}$, invitó a los

\footnotetext{
${ }^{19}$ Enrique del Piélago, "La gran tragedia. Para los alumnos de la escuela peruana", El Morro de Arica, 6 de junio de 1900.

${ }^{20}$ Gálvez, Carlos. 2015. "Francisco Bolognesi o la construcción del héroe”, en Mauricio Novoa, ed., Bolognesi, Lima, Ministerio de Defensa / Ejército del Perú, pp. 140-155.

${ }^{21}$ Monteverde, Rodolfo. 2017. "Política internacional de la posguerra del Pacífico, remodelación urbana y proyectos escultóricos de Lima: el monumento público a Francisco Bolognesi y los caídos en la batalla de Arica", en Historia, $\mathrm{N}^{\circ}$ 50, Vol. II, Santiago, pp. 663-697.

22 Véase, por ejemplo, la portada de El Morro de Arica, 8 de junio de 1907; y de La Voz del Sur, Tacna, 7 de junio de 1907.

23 "La romería del domingo al morro y las baterías", El Morro de Arica, 9 de junio de 1908.

${ }^{24}$ Cubas, Ricardo. 2018. "El presbítero Juan Vitaliano Berroa frente a la chilenización de Tacna y Arica (1904-1926): un caso de resistencia civil", en Patricio Ibarra y Germán Morong, eds., Relecturas de la Guerra del Pacifico: avances y perspectivas, Santiago, Ediciones Universidad Bernardo O’Higgins, pp. 215-254.
} 
escolares peruanos a meditar sobre el significado del Morro, que comparaba a un "altar", mientras que las olas del mar evocaban "el nombre de los héroes". La oración en aquel escenario de recogimiento debía interceder ante el "trono del Dios de las batallas, para que él derrame sobre el Perú los beneficios del triunfo de nuestra causa, como el fruto del sacrificio de Bolognesi y sus compañeros". ${ }^{25}$ El presidente de la Sociedad Juvenil Peruana de Socorros Mutuos, Juan Worm L., inspirado en la evocadora frase del héroe peruano - "Tengo deberes sagrados que cumplir y los cumpliré hasta quemar el último cartucho" - arengó al público insistiendo en que una actitud similar debía modelar la conducta de los peruanos residentes en Arica:

"Si algún día que creo no llegará jamás, nos sintiéramos desfallecer o amenguarse algo nuestro patriotismo, vengamos aquí, a respirar este aire purificado con la sangre de nuestros padres; dirijamos la vista a nuestro alrededor y cada sitio nos recordará un episodio llevado a cabo por nuestros antepasados; cada despojo nos traerá a la memoria el nombre de uno de esos guerreros que rindieron su vida en defensa de la integridad de nuestro territorio [...] Estemos preparados para acudir al llamado de nuestra patria y defenderla como la defendieron ellos 'hasta quemar el último cartucho'"26.

¿Cómo recordaba la comunidad chilena de Arica el 7 de junio en aquellos años? En este primer momento los esfuerzos chilenos fueron escasos y presentaron un bajo perfil mediático. En la prensa de la época es posible encontrar algunas referencias dispersas alusivas a misas de campaña o embanderamientos del Morro ${ }^{27}$. Tales instancias, sin embargo, fueron intentos tímidos de celebración de la efeméride, en general patrimonio de la burocracia chilena y el contingente militar del puerto. Y cuando hubo intentos de replicar la idea de romería al Morro, como se hizo en 1905, la ceremonia fue modesta y se limitó a la mañana, para no coincidir con la conmemoración peruana a realizarse en la tarde ${ }^{28}$. La excepción más notable dentro de ese primer ciclo conmemorativo fue la inauguración, en 1902, de una cripta con los restos de los combatientes de las batallas de Tacna y Arica, monumento instalado en el Morro. La ceremonia tuvo un carácter marcadamente castrense y concitó la participación de los veteranos radicados en ambas ciudades ${ }^{29}$. Los oradores de la actividad perfilaron en aquella ceremonia algunos lineamientos que serían claves y permanentes en la conceptualización chilena de la festividad. Para el intendente Jorge Boonen Rivera, veterano de la Guerra del Pacífico y a esas alturas General de Brigada, la batalla de Arica recordaba el alto costo humano que implicó su conquista

\footnotetext{
25 "Ecos del 7 de junio", El Morro de Arica, 11 de junio de 1908.

26 "Ecos del 7 de junio", El Morro de Arica, 13 de junio de 1908.

${ }^{27}$ Cf. "La misa de la autoridad chilena", El Morro de Arica, 9 de junio de 1900; "7 de junio de 1880", El Morro de Arica, 8 de junio de 1901.

28 "7 de junio", El Morro de Arica, 7 de junio de 1905.

29 "7 de junio", El Pacífico, Tacna, 5 de junio de 1902; "7 de junio de 1880", El Morro de Arica, 7 de junio de 1902.
} 
para la nación chilena. El monumento recordaba así a quienes "con su sacrificio dilataron las fronteras de la patria chilena" y permitieron enarbolar en la cima del Morro la bandera nacional ${ }^{30}$. Esa narrativa sería refrendada por las autoridades religiosas de la zona. José Julio Elizalde indicó que Arica era una "tierra comprada al precio de la sangre vertida por los ínclitos campeones que reposan en ella". En ella "la enseña tricolor flameará siempre sobre sus cúspides más altas y cubrirá con su serena sombra el humilde sepulcro de sus hijos, que aquí murieron para defender los fueros y el honor de la república", afirmaba. ${ }^{31}$

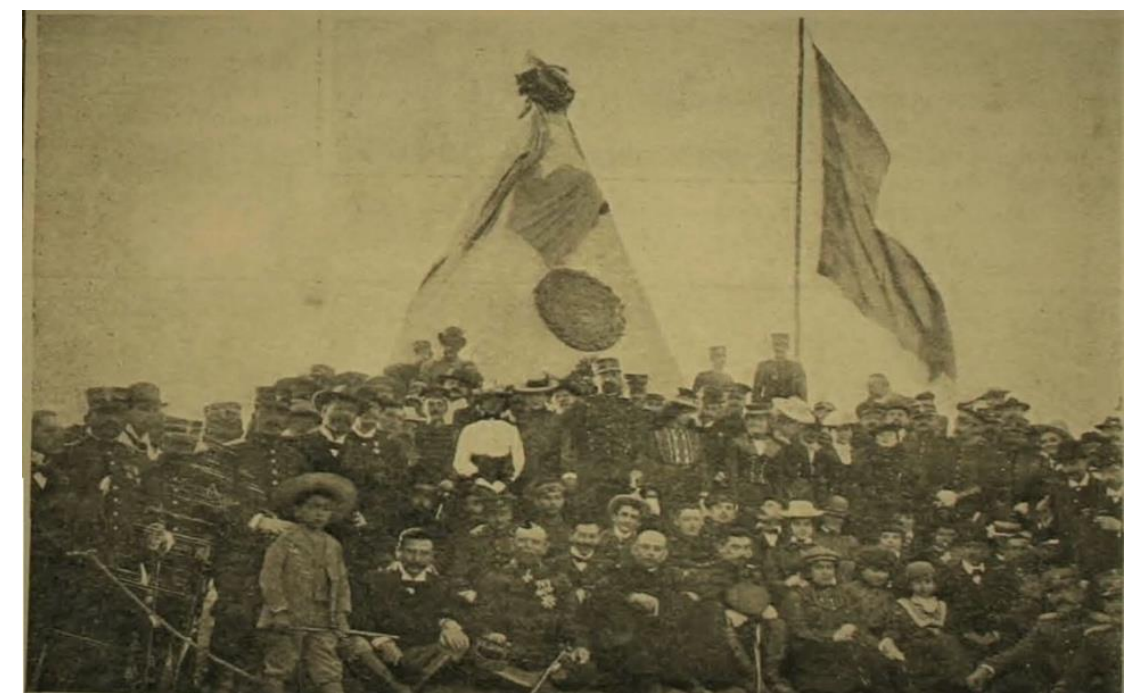

Imagen 1. Inauguración de cripta de los combatientes de Tacna y Arica, 7 de junio de 1902, Zig-Zag, N²86, 9 de abril de 1910.

\section{La chilenización de la conmemoración, 1909-1922}

En términos conmemorativos, el bienio de 1908-1909 representó un momento bisagra en las celebraciones del 7 de junio. En efecto, 1908 fue la última vez en que la comunidad peruanoariqueña recordó ritualmente la batalla de Arica, mientras que en 1909 los chilenos patrimonializarían la celebración, un factor que se extendería hasta fines del marco temporal aquí analizado. Este quiebre obedeció a procesos sociales más amplios en el Norte Grande, asociados a la radicalización que, en torno a la época del centenario, adquirieron las políticas de chilenización de la frontera y el discurso nacionalista ${ }^{32}$.

El despliegue de esas políticas comenzó en aspectos cotidianos, como el renombramiento de las calles de la ciudad. Dicho cambio era síntoma de procesos simbólicos mayores. Como ha

\footnotetext{
30 "Discursos", El Pacífico, Tacna, 10 de junio de 1902.

31 "Alocución", El Pacífico, Tacna, 11 de junio de 1902.

32 Díaz Aguad, Alfonso y Pizarro, Elías. 2004. "Tacna y Arica en tiempos del Centenario”, en Diálogo Andino, № 24, Arica, pp. 29-38.
} 
sugerido Olivier Ihl, las estrategias de renombramiento de la toponimia urbana son el resultado del despliegue de una "política simbólica" que concebía el bautismo de hitos de las ciudades como una utilización del espacio cotidiano para transmitir una pedagogía del valor cívico afines a la nación ${ }^{33}$. Así, en los días previos a la conmemoración del 21 de mayo de 1909, la Junta de Alcaldes de la ciudad dio un paso decisivo en su afán chilenizador abordando "la conveniencia que habría en cambiar el nombre a muchas calles de la ciudad, en vista de que muchos de ellos no tienen actualmente significado alguno, ni recuerdan nombres de personajes ilustres o fechas de acontecimientos notables que interese perpetuar en la memoria de pueblo". ${ }^{34}$ De cara a los festejos de septiembre, la Junta procedía a renombrar las calles de la ciudad, en una política explícita de chilenización que remitía, de modo esperable, a la Guerra del Pacífico como can tera de héroes y batallas para renombrar una ciudad en la que se leía el pasado peruano. De estos, debido a su peso específico, solo se libró la calle Bolognesi. Los nombres escogidos eran elocuentes: 7 de junio, Arturo Prat, General Baquedano, General Lagos, Blanco Encalada, Comandante San Martín, 18 de septiembre, O’Higgins, Chacabuco, Yungay, Manuel Thomson, Maipú y Sangra, entre otras ${ }^{35}$.

En ese ambiente proclive a la chilenización de la ciudad, resultan claves los esfuerzos desplegados en la nacionalización de la conmemoración del 7 de junio de 1909, especialmente por parte de la sociedad civil. Los festejos de aquel año, organizados por la Sociedad Chilena Unión y Patriotismo, la Sociedad Chilena Unión de Socorros Mutuos, los veteranos y militares acantonados en Tacna, además de los empleados del ferrocarril, quebraron el monopolio peruano de la fecha. La celebración, que convocó a unas 500 personas, incluyó una misa y la tradicional romería hacia el Morro, esta vez conceptualizado como el espacio donde se desplegó la superioridad militar chilena, un lugar donde "la intrepidez y la impetuosidad del soldado chileno se ha comprobado una vez más", como sostuvo un publicista ${ }^{36}$. El discurso principal de la ceremonia lo brindó, de hecho el veterano José Mercedes Díaz, remarcando el espíritu de nacionalismo marcial que adquirió el ritual por esos años ${ }^{37}$.

Al año siguiente, en el marco de los festejos del centenario de la independencia chilena, las ceremonias volvieron a caracterizarse por la gran cantidad de participantes - destacando la población escolar, además de las asociaciones obreras - por la fastuosidad de las ceremonias

\footnotetext{
$33 \mathrm{Ihl}$, Olivier. 2002. "La monumentalisation de la voi publique. Sur les politiques d'attribution des noms de rue aux XIX' et XXe siècles", en Philippe Poirrier (dir.), Les collectivités locales et la culture, París, La Documentation Française /Comité d'Histoire du Ministère de la Culture, pp. 127-144.

34 Junta de Alcaldes de Arica, acta de la sesión de 19 de mayo de 1909, en Biblioteca Nacional de Chile, Sala Medina, Archivos Documentales, caja 23, doc. 307. Véase también "Los nombres de las calles", El Ferrocarril, Arica, 23 de mayo de 1909.

35 Junta de Alcaldes de Arica, acta de la sesión de 11 de septiembre de 1909, en Biblioteca Nacional de Chile, Sala Medina, Archivos Documentales, caja 23, doc. 308.

${ }^{36}$ A. de Norjal, "La semana”, El Ferrocarril, 6 de junio de 1909.

37 "El 7 de junio en Arica. Grandiosa romería patriótica”, El Ferrocarril, 10 de junio de 1909.
} 
y el carácter carnavalesco que se le dio a las fiestas, como lo reflejó la instalación de ramadas en la cima del Morro ${ }^{38}$. En uno de los discursos pronunciados en la cima del Morro y a los pies de la bandera chilena, el estudiante del Instituto Comercial de la ciudad, Luis Ruiz, estableció la continuidad de sentimientos entre los soldados de 1880 y su generación, que tenía ahora la misión de preservar las conquistas territoriales de la guerra: "Esa herencia nos liga indisolublemente al pasado y nos dicta nuestra conducta del porvenir. Delante del mar que baña nuestras playas; sobre esta cumbre sembrada de ruinas y recuerdos, nosotros los niños pedimos una sola cosa: que nuestro país no olvide las glorias de su pasado guerrero, ni desprecia las glorias de su futura paz", concluía. ${ }^{39}$

Por cierto, este cambio discursivo y ritual no pasó inadvertido para los medios peruanos. Los festejos chilenos eran "una ofensa dolorosa y gratuita para la colectividad peruana que tiene su hogar en estos territorios", señaló La Voz del Sur. Dado que el 7 de junio tenía el carácter de "aniversario fúnebre para estos pueblos", las fiestas chilenas reflejaban insensibilidad con el "dolor ajeno" y falta de hidalguía hacia los vencidos, ofreciendo bailes "encima de las tumbas de los adversarios que cayeron en esas jornadas defendiendo su bandera, en medio de nuestros hogares desolados por el infortunio y por la muerte" ${ }^{40}$. El periódico tacneño no estuvo solo en este diagnóstico. Más fuertes fueron las críticas de El Morro de Arica, para el cual las celebraciones de aquel año fueron "más pomposas todavía que con que se celebra el aniversario chileno", lo que era "una ofensa estudiada para los peruanos residentes en estos territorios, la mayor parte de los cuales perdieron un deudo, un amigo en la hecatombe del Morro". Lo penoso no solo era la monopolización chilena de la efeméride, sino el carácter festivo que se le confirió. Como hemos indicado, la comunidad peruano-ariqueña representaba el aniversario del 7 de junio desde la perspectiva reverencial de la admiración por el sacrificio. Por eso, el establecimiento de ramadas y chinganas chilenas en la cima del Morro resultaba un verdadero acto de "profanación que ha arrancado un grito de protesta general del pecho de todos los peruanos", al realizar en aquel sitio histórico "libaciones y otros actos impropios de otro pueblo culto". Este tipo de acciones desde los sectores chilenos solo contribuían "a mantener viva la herida" entre los vencidos. ${ }^{41}$

La "herida" simbólica reabierta por los chilenos por su particular forma de conmemorar la toma del Morro de Arica fue, en realidad, uno de los primeros síntomas de la radicalización del proceso de chilenización de la frontera norte. De hecho, ese mismo año las autoridades chilenas expulsaron a los curas peruanos de la provincia, y en 1911 la violencia, que transitó desde su dimensión simbólica a una física, pasó a tener un rol preponderante por grupos nacionalistas

\footnotetext{
38 "Las fiestas del 7. Entusiasmo popular", El Ferrocarril, 9 de junio de 1910.

39 "Una nota culminante", El Ferrocarril, 9 de junio de 1910.

40 "Fiesta inconsulta", La Voz del Sur, Tacna, 6 de junio de 1910.

41 "Enconando la herida. Las fiestas de hoy", El Morro de Arica, 7 de junio de 1910.
} 
como los "mazorqueros". En tal contexto se llevaron a cabo hechos de violencia como los ataques a las imprentas peruanas de la zona, locales comerciales, la demolición del Club Unión o el ataque contra un sitio de alto valor simbólico para la comunidad peruana de la ciudad, como la casa de Bolognesi ${ }^{42}$.

En adelante, la conmemoración se mantuvo, recuperando fuerza a mediados de la década de 1910 con de la inauguración del monumento a Benjamín Vicuña Mackenna a los pies del Morro. Las gestiones para trasladar el monumento desde Santiago hacia el norte se iniciaron en la época del centenario, a instancias de la Liga Patriótica Militar. El simbolismo del monumento del polígrafo chileno y el Morro era decisivo para la comunidad chilena. "iNo soltéis el Morro!", proclamó en 1880 el prolífico historiador, indicando que este debía permanecer perpetuamente como el reflejo de la nueva frontera norte del país. Aunque la sociedad civil ariqueña intentó hacer coincidir las multitudinarias festividades de 1916 con la inauguración ${ }^{43}$, los preparativos se extendieron llevándose a cabo algunos días después. La multitudinaria ceremonia, que congregó a las escuelas públicas de la ciudad y de Tacna, la Sociedad de Veteranos, las sociedades obreras, bomberos y los regimientos de la zona, sirvió para reivindicar el discurso expansionista chileno, insistiendo en la idea de aferrarse al territorio conquistado y no devolverlo al Perú. Tal fue la enseñanza principal que había legado a sus compatriotas Vicuña Mackenna, el "gran intérprete del sentimiento chileno". Eso fue lo que remarcó el alcalde de la ciudad en su discurso, subrayando además la labor civilizatoria chilena: "Quedaremos aquí para trabajar y hacer que prosperen estas tierras", "quedaremos para hacer salubres localidades que antes fueron focos de infección; el que aquí llegue encontrará justicia, amparo a todas las creencias y dentro de la libertad haremos reinar el orden", indicaba Juan Manuel Valle ${ }^{44}$.

En los años siguientes la conmemoración siguió un patrón ritual bastante estable, sufriendo escasas modificaciones. La relevancia nacionalizadora de las fiestas cívicas tuvo un importante impulso desde las autoridades. Así, un decreto municipal del 4 de mayo de 1915 ordenaba el embanderamiento obligatorio de las viviendas locales en días festivos, so pena de multas. El mismo presupuesto para estas instancias aumentó considerablemente. En 1919, por ejemplo, los gastos destinados a financiar fiestas cívicas eran la mitad de todo el presupuesto para instrucción pública en el departamento ${ }^{45}$.

\footnotetext{
42 González, Sergio. 2008. La llave y el candado, p. 44; Skuban, William. 2007, Lines in the Sand, p. 51.

43 "Ecos del 7 de junio", El Ferrocarril, 9 de junio de 1916; "Ecos del 7 de junio", La Aurora, 18 de junio de 1916.

44 "La inauguración del monumento a Benjamín Vicuña Mackenna", La Aurora, 25 de junio de 1916; "La apoteosis del domingo", La Aurora, 25 de junio de 1916. Véase además García, Juan Carlos. 2000. "El monumento a Benjamín Vicuña Mackenna en Arica", en Anuario del Instituto de Conmemoración Histórica de Chile, N 5, Santiago, pp. 57-60. 45 "Memoria del Gobernador del Departamento de Arica", 1919, en Biblioteca Nacional de Chile, Sala Medina, Archivos Documentales, caja 22, vol. 74, doc. 285.
} 


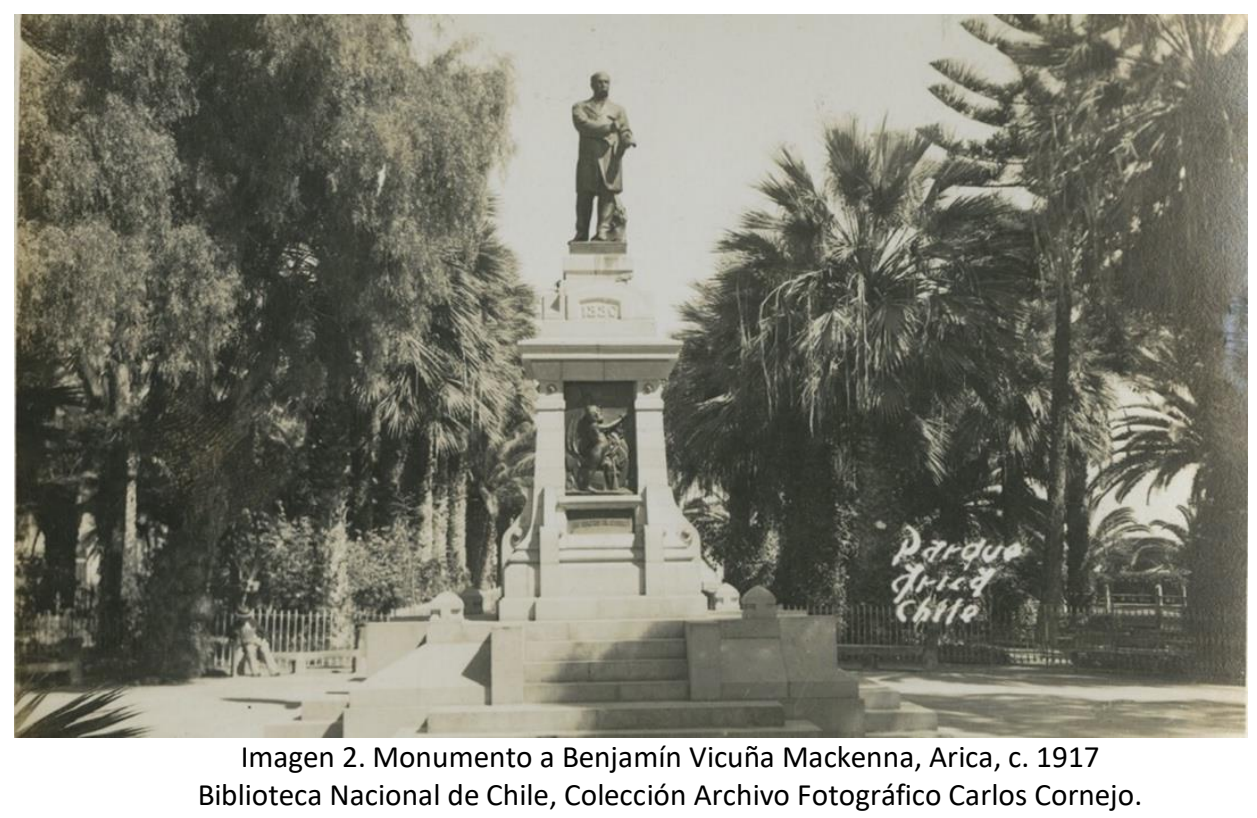

En general, las conmemoraciones comenzaban con una misa de campaña que incluía habituales sermones patrióticos que refrendaban la labor nacionalizadora que estaba desempeñando el clero en aquellos años ${ }^{46}$. Junto al discurso religioso, las conferencias militares llevadas a cabo en el espacio del Teatro Nacional se encargaron de actualizar frente al auditorio el relato histórico de la toma del Morro por las fuerzas chilenas, instancia que servía para remarcar la idea de superioridad militar y exaltar el nacionalismo desde un registro castrense ${ }^{47}$. El espacio de la oratoria pública fue decisivo en estas ceremonias. De probado efecto en la interpelación emotiva al auditorio y en la capacidad de persuadir masivamente mediante las habilidades retóricas de los tribunos ${ }^{48}$, esta tuvo un sitial privilegiado en cada una de las conmemoraciones: en la cima del Morro, en las escuelas, en la plaza Colón, a los pies del monumento a Vicuña Mackenna o en el Teatro Nacional, los hombres de palabra reivindicaron una y otra vez la historia de la toma de Arica, en clave de epopeya de una "raza guerrera". Fue lo que sostuvo Celedonio Gutiérrez, operario de la Maestranza Chinchorro que dio el discurso principal a los estudiantes de las escuelas públicas en el Morro en 1918: "Leed con devoción la historia de la raza, en ella aprenderéis que desde Caupolicán y Lautaro, hasta Prat, Ramírez, San Martín y Lagos han seguido incólumes su gloriosa tradición". "Aprenderéis también que un país

\footnotetext{
46 "Ecos del 7 de junio", La Aurora, 9 de junio de 1917. Allí se inserta, por ejemplo, el sermón brindado por el presbítero Zócimo Valenzuela.

${ }^{47}$ Cf. "La conferencia de jueves", La Aurora, 9 de junio de 1917; o “Conferencia patriótica”, La Aurora, 7 de junio de 1919.

${ }^{48}$ Cf. Vicuña, Manuel. 2003. Hombres de palabras. Oradores, tribunos y predicadores, Santiago, Sudamericana / Centro de Investigaciones Diego Barros Arana.
} 
pequeño ha sido siempre cuna de valientes que con sus hechos hermosos han causado con justicia la admiración del mundo", concluía el obrero. ${ }^{49}$

Además de las discursos y conferencias, los desfiles militares, las retretas y las actividades recreativas en el Teatro Nacional fueron instancias que se posicionaron como tradiciones en aquellos años. Los actores colectivos más relevantes fueron la población escolar y los scouts, que se convirtieron en el auditorio más sistemáticamente expuesto a los ritos patrióticos de aquellos años ${ }^{50}$. En paralelo, la presencia de los veteranos de la guerra de 1879 fue cada vez más significativa en los rituales, destacando la figura de la cantinera Filomena Valenzuela, convertida en una verdadera celebridad pública ${ }^{51}$.

En el bienio 1920-1921 la fiesta alcanzó un importante impulso, en buena medida como resultado del recrudecimiento de las tensiones fronterizas que, en 1920, llevaron incluso a la movilización de los regimientos de ambos países a lo largo de la frontera y conllevó un escalamiento en la virulencia del discurso nacionalista. Desde Lima, por ejemplo, en las páginas de Rojo y Blanco, caracterizada como el medio de "los peruanos de Tacna, Arica y Tarapacá" se hizo un llamado a "militarizar al Perú" de cara a una eventual recuperación territorial: "La sangre derramada por nuestros padres reclama venganza y justicia; la voz de los muertos, desde el fondo de sus gloriosas sepulturas, nos dice que cumplamos cuanto antes el imperativo del deber que nos señala la ruta del sur, por donde deben ir nuestros soldados a conquistar la reintegración de la patria mutilada", sentenciaba Amadeo Delgado ${ }^{52}$. En Arica las respuestas no se hicieron esperar y las ceremonias patrióticas se multiplicaron durante ese período, intentando reivindicar la presencia chilena en la zona, utilizando el pasado bélico como cantera evocadora del nacionalismo. Los chilenos, afirmaba un periodista tras comentar uno de estos rituales cívicos, "tenemos un pasado tan brillante y ejemplar que guarda Chile en su historia inconcebible una fuente inagotable de inspiración para sus hijos". De ahí, agregaba, la confianza en que "la hegemonía de la raza triunfará" 53 .

En dicho escenario amenazante, cualquier disidencia frente al impulso nacionalista en la frontera era fuertemente denunciado. En este sentido, quienes no se plegaban de manera entusiasta a estas actividades eran criticados por la prensa como "antipatriotas" y "comunistas". Eran ellos, afirmaba un medio, quienes "no guardan reparo en pregonar voz en

\footnotetext{
49 "Las fiestas de ayer", La Aurora, 8 de junio de 1918.

50 Cf. "Conmemoración del 7 de junio" La Aurora, 7 de junio de 1919; "Como celebramos el 40 aniversario de la gloriosa toma del Morro", La Aurora, 6 de junio de 1920; "El próximo aniversario de la toma del Morro", La Aurora, 27 de mayo de 1921.

51 "Filomena Valenzuela en la Misa y en el Instituto Comercial", La Aurora, 9 de junio de 1917; "Doña Filomena Valenzuela", La Aurora, 6 de junio de 1920; "La señora Valenzuela", La Aurora, 7 de junio de 1921.

52 Amadeo Delgado, "El ideal de la revancha", Blanco y Rojo, Lima, n 5, 1 de octubre de 1920, p. 189.

53 "En demanda de sus respectivos cuarteles", La Aurora, 22 de julio de 1920. Véase también "El gran desfile patriótico de ayer", La Aurora, 22 de julio de 1920 y "El comicio público de hoy", La Aurora, 25 de julio de 1920.
} 
cuello que la patria es un figurín sin propiedad y a la vez sentimental", llevando con su prédica a una verdadera "crisis de patriotismo" 54 . En la víspera de la conmemoración del 7 de junio, El Heraldo, el medio de la Federación Obrera de la zona, publicó un artículo en que cuestionaba los móviles de la Guerra del Pacífico y, por extensión, del nacionalismo chileno: "La guerra se produjo para defender los intereses de los capitalistas; y no para defender la integridad de la nación", afirmaba el artículo que fustigaba a los "patrioteros". El concepto de "patria", aseguraba, era solo una "pantalla para defender los intereses de los capitalistas chilenos, ingleses, franceses, alemanes y peruanos" 55 .

El rumor de que los miembros de la Federación Obrera no participarían ese año en las festividades cívicas fue denunciado como el inevitable resultado de "las doctrinas disolventes que allí se alimentan entre algunos dirigentes"56. Esa actitud antipatriótica, "el credo de Judas", era propio de quienes vivían del "peregrinaje mendicante de frontera en frontera" y no amaban a Chile y su historia, sentimiento impropio en medio de los desafíos diplomáticos que enfrentaba la región ${ }^{57}$. La conmemoración de la batalla de Arica de ese año debía ser multitudinaria y no dar pie a dudas del arraigado patriotismo de los chilenos, sugería el medio. En efecto, las celebraciones fueron multitudinarias ${ }^{58}$ y la presión social sumada a la hegemonía del nacionalismo como discurso público en la zona obligó a los representantes de la Federación Obrera a acudir a las ceremonias. En ese escenario, Simón Pino, el trabajador que fungió como orador en las actividades conmemorativas en representación de la Federación, tuvo que subrayar que Tacna y Arica debían permanecer bajo la égida chilena, porque su desarrollo había sido el resultado del esfuerzo de los trabajadores nacionales. Sin embargo, y tensionado entre los discursos nacionalistas y obreristas, el operario del ferrocarril hizo un llamado a la fraternidad en la frontera, homenajeando "a vencedores y vencidos, ya que ellos confundidos en la muerte, cayeron con idénticos propósitos". ${ }^{59}$

\section{De la chilenización compulsiva a la conciliación: la conmemoración entre 1922-1929}

El último momento que examinamos en estas páginas es el comprendido entre 1922 y 1929 . Se trata de un período de recrudecimiento de las políticas de nacionalización del territorio y de un uso compulsivo, sistemático y masivo de los rituales patrióticos como mecanismo de

54 “Crisis de patriotismo", La Aurora, 31 de mayo de 1921.

55 “iPatrioteros!", El Heraldo, 4 de junio de 1921.

56 "Rememoración del 7 de junio", La Aurora, 31 de mayo de 1921.

57 “Antipatriotismo", La Aurora, 3 de junio de 1921.

58 "Las fiestas del 7 de junio", La Aurora, 9 de junio de 1921.

59 "Conmemoración del 7 de junio", El Heraldo, 8 de junio de 1921. Las tensiones entre las identidades nacionales y obreras en el seno de dicha asociación en la zona han sido analizadas por Soto Lara, José. 2013. "La Federación Obrera de Chile (FOCH) como movimiento popular nacionalista en Arica (1920)", en Tradición y Saber, Vol. 10, N², Santiago, pp. 65-84 
chilenización. Ese momento está enmarcado por la incertidumbre internacional ante el diferendo limítrofe y la inminente realización del plebiscito. La judicialización internacional del conflicto ante la Sociedad de Naciones y la apelación al arbitraje internacional de EE.UU. a propósito de las conferencias de Washington entre mayo y julio de 1922, aceleró las políticas de chilenización de la frontera ante la ratificación de la fórmula plebiscitaria. El discurso nacionalista también se hizo más explícito en su reivindicación de aquellos territorios. Ellos, decía El Morro, "son y serán eternamente chilenos, y que para que dejen de serlo es menester que una raza más fuerte y poderosa haya hecho desaparecer previamente a todos los chilenos capaces de sostener una bandera en sus manos y de arrancarse el corazón antes que permitir una traición a su patria"60.

Dicho contexto enmarcó una serie de políticas conmemorativas alusivas a la guerra, que incidieron en el espacio público y estimularon el uso del ritual cívico, especialmente en las aulas. Así, por ejemplo, en mayo de 1922 la Junta de Alcaldes de Arica determinó el cambio de nombres de las calles de Putre, reemplazándolos por topónimos chilenos asociados al conflicto de 1879. Al mes siguiente, los soldados del Regimiento Rancagua de la ciudad erigieron a los pies del Morro el monumento al comandante Juan José San Martín, uno de los soldados chilenos caídos en la batalla, ícono que servía para transmitirle a los lugareños "que esta tierra es nuestra porque nuestros antepasados la ganaron con su sangre y su valor"61. Las escuelas, como veremos, tuvieron un rol destacadísimo en un escenario, además, de implementación de la ley de instrucción primaria obligatoria en el país. No sin razón Jorge Basadre recordó cómo en una de sus visitas a Arica a inicios de la década de 1920 las escuelas "servían como agencias de propaganda continua", obligándoseles a los estudiantes a portar escarapelas chilenas y cantar compulsivamente himnos patrióticos. No fueron las únicas protagonistas. Junto a las tradicionales sociedades de veteranos, agrupaciones de la sociedad civil como la Sociedad de Hijos de Tacna y Arica y el Comité Cívico - organizaciones "de carácter paramilitar y semifascista", al decir de Basadre ${ }^{62}$ - desempeñaron un rol clave en las políticas conmemorativas del período.

De manera sintomática, la pulsión conmemorativa de aquellos años llevó incluso a chilenizar festividades como el aniversario patrio peruano. Tal fue la política que en 1922 defendió la Sociedad de Instrucción Popular, organización clave en la socialización nacionalista de la zona ${ }^{63}$. En los festejos del centenario de la independencia del Perú, Chile fue "el gran ausente de la

\footnotetext{
60 “El plebiscito", El Morro, 15 de julio de 1922.

61 "La inauguración del monumento al comandante San Martín", La Aurora, 9 de junio de 1922.

62 Basadre, Jorge. 1974 "Los conflictos de pasiones y de intereses en Tacna y Arica (1922-1929)", en Historia y Cultura, $N^{\circ} 8$, Lima, pp. 11-12.

63 Soto, José y Chávez, Pablo. 2016. "El nacionalismo de la Sociedad de Instrucción Popular de Arica (1914-1925)", en Cuadernos Chilenos de Historia de la Educación, N 5, Santiago, pp. 21-46.
} 
fiesta peruana" por las tensiones diplomáticas de Tacna y Arica, recuerda Pablo Ortemberg ${ }^{64}$. En la velada, que se llevaría a cabo en el Teatro Nacional, debía recordarse al auditorio que la independencia peruana fue "hecha por Chile, con soldados chilenos, buques chilenos, dinero chileno y bajo la bandera de Chile". Y eso, agregaban los organizadores, había sido olvidado por el país vecino: "Jamás podrá el Perú borrar el baldón de esta ingratitud". "Si el Perú no se acuerda de nosotros, acordémonos nosotros de él. Celebremos su independencia por cuenta nuestra, porque es obra nuestra", afirmaba el comunicado ${ }^{65}$. El ritual patriótico fue multitudinario: dos mil personas asistieron a la conferencia brindada en el teatro por Luis Méndez Bravo, el visitador de las escuelas de la provincia. Luego se realizó un desfile por las calles de la ciudad. En la Plaza Colón, en el meeting realizado allí el orador de la ceremonia Isaac Gálvez insistió en la ingratitud peruana "para los que derramaron su sangre para darle independencia y formarlo como nación soberana". El 28 de julio es "una gloria chilena que hasta ahora pasaba inadvertida por una injusticia histórica. En lo sucesivo, esa fecha será nuestra, porque nos pertenece mucho más a nosotros que a los peruanos" ${ }^{\prime 66}$.

En ese marco de sensibilidades deben entenderse los ritos cívicos del 7 de junio. Los festejos de 1922, por ejemplo, tuvieron un carácter marcadamente castrense -en buena medida por la inauguración del monumento a Juan José San Martín-e incluyeron la participación compulsiva de scouts y escolares, quienes durante el día previo recibieron conferencias en sus colegios y luego entregaron flores a los pies del monumento escoltado por veteranos de la guerra. Así, los festejos incluyeron desfiles militares, retretas, fiestas populares, además de fuegos artificiales lanzados desde el Morro ${ }^{67}$.

Los años siguientes siguieron un patrón ritual bastante similar. Además de los desfiles militares, se sumaban misas de campaña con la presencia de veteranos. La locación de estas ceremonias a veces se realizaba a los pies del Morro o del monumento a Benjamín Vicuña Mackenna. El Teatro Nacional, asimismo, fue un espacio clave en la socialización de los discursos patrióticos, por medio de la realización de conferencias históricas y representaciones alegóricas al auditorio local ${ }^{68}$. Las escuelas tuvieron un rol decisivo. Las ceremonias incluían su presencia compulsiva, y en el espacio escolar se llevaban a cabo conferencias patrióticas

\footnotetext{
${ }^{64}$ Ortemberg, Pablo. 2016. "Los centenarios de 1921 y 1924, des de Lima hacia el mundo: ciudad capital, experiencias compartidas y política regional”, en Alex Loayza, ed., La independencia peruana como representación. Historiografía, conmemoración y escultura pública, Lima, Instituto de Estudios Peruanos, p. 146.

65 "Una gran velada patriótica”, El Morro, 26 de julio de 1922.

66 “La imponente manifestación cívica de anoche”, El Morro, 29 de julio de 1922.

67 "Celebración del 7 de junio. Programa oficial para conmemorar el $42^{\circ}$ aniversario de la toma del Morro de Arica", La Aurora, 6 de junio de 1922.

68 Véase "Programa oficial", La Aurora, 6 de junio de 1923; "Los actos conmemorativos de la toma del morro", La Aurora, 9 de junio de 1923; "Programa oficial”, La Aurora, 6 de junio de 1924; "Grandiosa representación de la toma del Morro de Arica", La Aurora, 7 de junio de 1924; y “Para el 7 de junio", La Aurora, 5 de junio de 1925.
} 
alusivas a la batalla. Incluso estas eran ofrecidas por los mismos veteranos ${ }^{69}$. Periódicos escolares locales como El Estudiante, por ejemplo, utilizaban la fecha como instancia privilegiada para fomentar el sentimiento nacionalista, una especie de emoción reverente ante "imagen sacrosanta de la patria" y "nuestros soldados mártires", como los caídos chilenos en la toma de $\mathrm{Arica}^{70}$. La idea de una nación invicta en sus combates y la bravura de los chilenos "el ejército más aguerrido de la tierra" - demostradas el 7 de junio eran alicientes para que los estudiantes luchasen para "mantener a costa de cualquier sacrificio las tradiciones de gloria que nos legaron nuestros invictos antepasados", indicó el educador Guillermo Cáceres. ${ }^{71}$

La música patriótica tuvo un lugar también importante en la socialización nacionalista alusiva a la toma del Morro en el espacio escolar. En 1923 el profesor Luis Villarreal compuso el "Himno Guerrero al 7 de junio", cantado en adelante por las escuelas en cada conmemoración ${ }^{72}$. Posteriormente sería impreso para ser cantado a nivel nacional. La letra remarcaba tópicos discursivos centrales de la versión chilena de la conmemoración, asociada al nacionalismo belicista, el carácter invicto de la república y la idea de mantención a toda costa de la soberanía en territorios conquistados por la guerra:

\footnotetext{
"A las armas soldados chilenos

Al combate, cantando volad

Tenga el canto una sola palabra:

Avanzad! Avanzad! Avanzad!"

Oh chilenos! El rudo combate

nos dio siempre glorioso laurel,

Que el escudo de un hijo de Chile es el lema «morir o vencer» Nunca pudo el acero enemigo abatirnos en tierra ni en mar Que lo digan Carrera y O'Higgins Que lo diga el recuerdo de Prat" ${ }^{73}$.
}

\footnotetext{
69 "La veterana Filomena Valenzuela en la Escuela Superior de Niñas", La Aurora, 11 de junio de 1924.

70 "El histórico morro", El Estudiante, 7 de junio de 1928.

${ }^{71}$ Guillermo Cáceres, "La epopeya del morro", El Estudiante, 7 de junio de 1928.

72 "Homenaje a los héroes", La Aurora, 6 de junio de 1923.

73 Villarreal, Luis. 1926. Gloria al 7 de junio: himno guerrero, recuerdo del plebiscito, Santiago, Casa Amarilla, p. 2.
} 


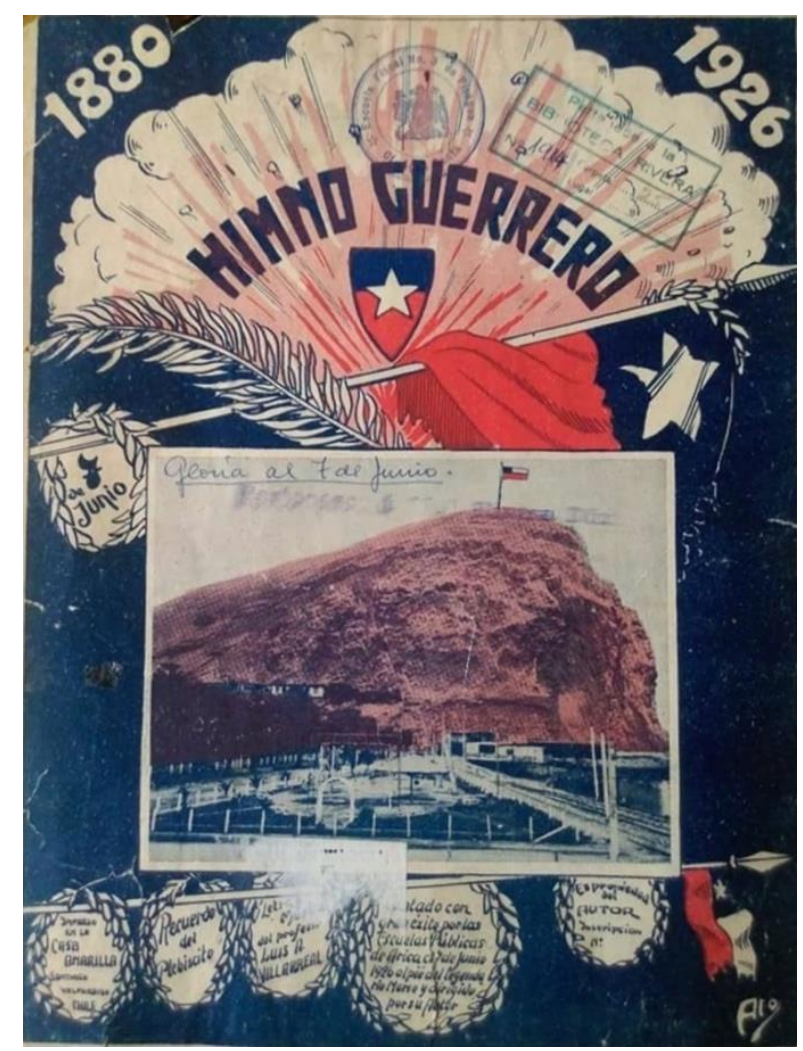

Imagen 3. Luis E. Villarreal, Gloria al 7 de junio: himno guerrero.

Colección Biblioteca Nacional de Chile, Archivo de Música.

Las ceremonias de 1925 profundizaron las instancias de socialización nacionalista en la población escolar y contaron con el apoyo cada vez más relevante en su implementación de organizaciones como la Asociación de los Hijos de Tacna y Arica. Sin duda, la cesión territorial de Tarata durante aquel año incidió en el impulso nacionalista y en el ascenso del discurso que reivindicaba la idea de mantener a ultranza los territorios conquistados tras la guerra, simbolizados en el Morro: "Nuestros padres lo ganaron con su sangre; los hijos hemos terminado la conquista en plena paz; nuestros descendientes sabrán mantener dignamente con su empuje y con su esfuerzo", editorializó El Ferrocarril ${ }^{74}$. El discurso fue reiterado por Álvaro Oliva, presidente de la agrupación nacionalista en la manifestación pública realizada ante el gobernador de la ciudad, quien enfatizó la necesidad de preservar aquellas tierras "regadas con la sangre generosa del valiente soldado chileno". "Nacimos en Chile, vivimos en Chile, y por lo

\footnotetext{
74 "El Morro", El Ferrocarril, 6 de junio de 1925.
} 
tanto, debemos defender todo lo que sea chileno porque ello importa nada menos que la defensa de nuestro honor jamás hollado", concluía. ${ }^{75}$

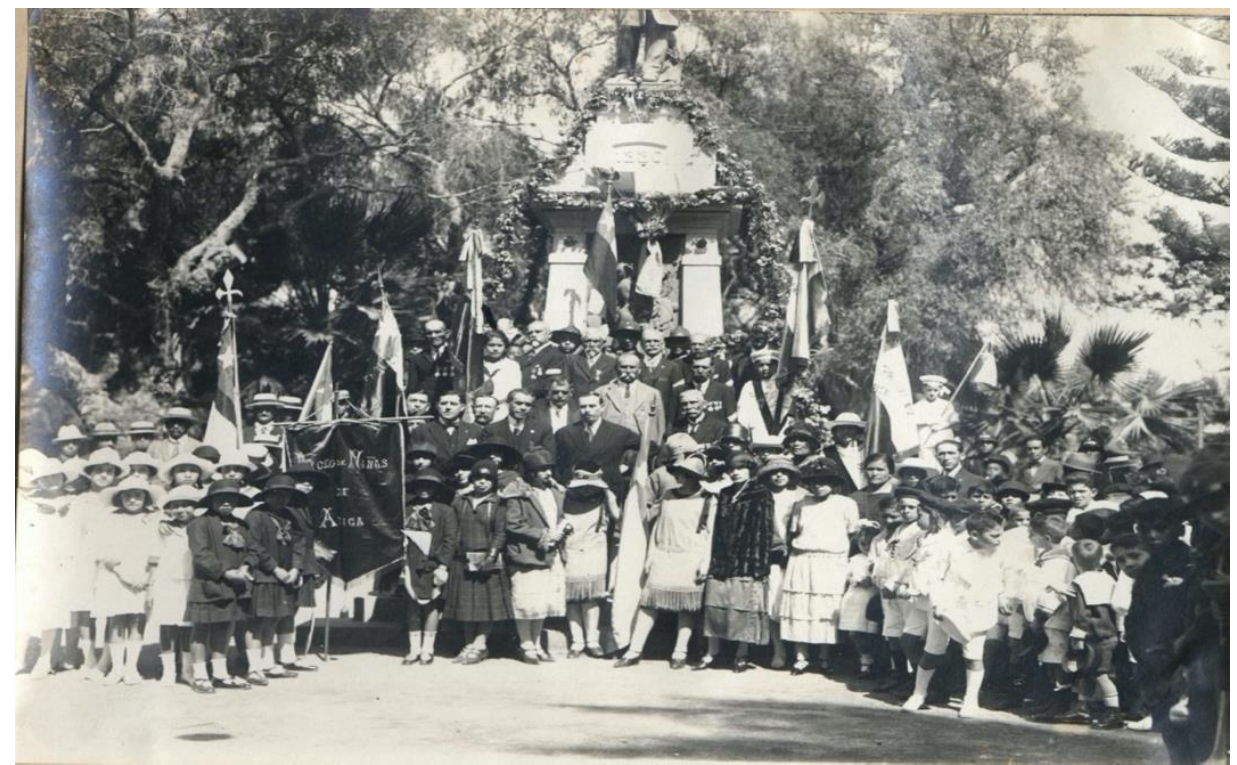

Imagen 4. Homenaje a los veteranos de la Guerra del Pacífico, Arica, 7 junio de 1926. Biblioteca Nacional de Chile, Colección Sala Medina.

La innovación más significativa instalada en las ceremonias de aquel año fue la implementación del ritual de la jura a la bandera, acto patriótico que en otras regiones del país en general se hacía coincidir con la efeméride del 9 de julio, el combate de la Concepción. Considerando el profundo arraigo de la conmemoración de la batalla de Arica en la cultura local este cambio en las fechas no debería sorprender. Un grupo de scouts del Instituto Comercial del puerto realizó el ritual al pie del monumento a Vicuña Mackenna. El teniente Milcíades Contreras, quien encabezó la ceremonia, explicó el simbolismo del rito a los escolares: "Esta bandera que preside la solemnidad de esta fiesta y que tan solo al contemplarla vivifica y enardece los sentimientos de patriotismo de todo chileno, ha sido inspiradora de actos de heroísmo que no registra la historia militar de otros pueblos". Por eso, los jóvenes debían prometer ser dignos depositarios de los valores allí encarnados ${ }^{76}$.

En 1926 las conmemoraciones tuvieron un carácter multitudinario. El antecedente de la cesión de Tarata a fines del año anterior y la inminencia del plebiscito eran elementos que volvían importante la conmemoración de la batalla de Arica. Particularmente intensos fueron

\footnotetext{
75 "La grandiosa manifestación de los nativos al gobernador y comandante de armas señor Emiliano Bustos León", La Aurora, 8 de junio de 1925.

76 “Discurso pronunciado ayer por el teniente del ejército señor Milcíades Contreras durante la solemne jura de la bandera, por los scouts del Instituto Comercial", El Ferrocarril, 8 de junio de 1925.
} 
los llamados desde la Asociación de Hijos de Tacna y Arica y de los círculos de veteranos para participar en la conmemoración. Las celebraciones incluyeron desfiles militares, de scouts y el juramento a la bandera en las escuelas. Incluso se movilizaron delegaciones desde Tacna para darle una impronta multitudinaria a la festividad ${ }^{77}$. El discurso convocante insistía en que las provincias de Tacna y Arica pertenecían a Chile, como lo simbolizaba la bandera flameando en la cima del Morro: "Esa gentil bandera puesta ahí por el esfuerzo y la audacia de nuestros gloriosos antepasados, deberá permanecer en el sitio en que aquellos la dejaron y no somos nosotros, por cierto, los que nos atrevamos a profanar la memoria de nuestros sagrados muertos, transigiendo con partijas o cesiones vergonzosas", afirmaba Arturo Velos Pérez ${ }^{78}$. Los veteranos, de destacado papel, también insistieron en un registro similar. Un grupo de ellos, a los pies del monumento a Vicuña Mackenna, hizo un llamado a los reservistas para defender el territorio en caso de una cesión diplomática ${ }^{79}$. Luis F. Gassols, veterano de la batalla apoyó esta afirmación, indicando que ceder un trozo del territorio ganado en la guerra era: "despreciar, dejar pisotear las cenizas de nuestros hermanos que reposan en el Campo de la Alianza y el Morro de Arica. Es atropellar, masacrar los derechos de los nativos de propios y extraños, que bajo el pabellón chileno fundaron sus hogares y sus esperanzas en estos sitios confiados en la grandeza e hidalga prosperidad de Chile" ${ }^{80}$.

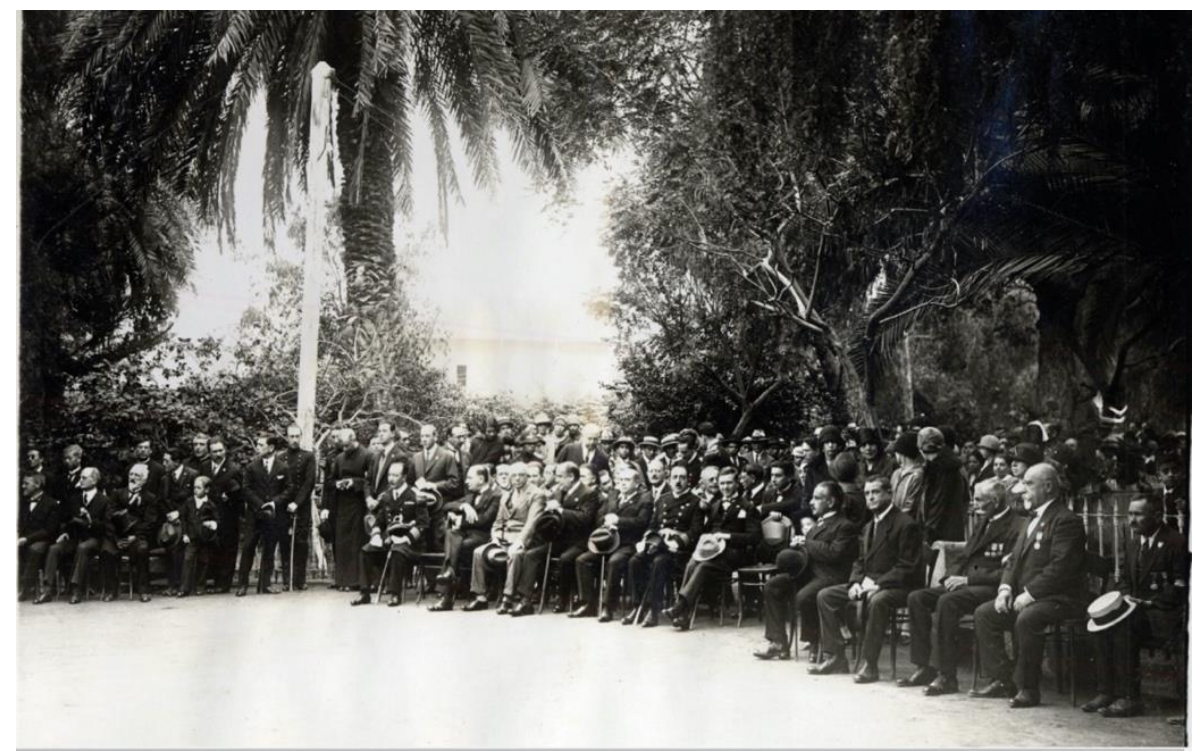

Imagen 5. Ceremonia conmemorativa del 7 de junio, Arica, 1926.

Biblioteca Nacional de Chile, Colección Sala Medina.

\footnotetext{
77 "7 de junio", El Ferrocarril, 8 de junio de 1926.

78 Arturo Velos Pérez, "7 de junio", La Aurora, 6 de junio de 1926.

79 "Una memorable sesión de los veteranos del 79", La Aurora, 9 de junio de 1926.

80 Luis F. Gassols, “¿Qué es la patria?”, La Aurora, 10 de junio de 1926.
} 
A diferencia de la escalada nacionalista de aquellos años, las conmemoraciones de la batalla de Arica en 1929 tuvieron un sentido diferente, brindado por los resultados del Tratado de Lima que el 3 de junio zanjó el diferendo limítrofe, reintegrando el departamento de Tacna a la soberanía peruana mientras que Arica quedaría en posesión del Estado chileno. En términos simbólicos, el mismo Morro sería desartillado de acuerdo con lo estipulado en el convenio y se establecía la necesidad de ubicar en su cima un monumento con el propósito de "conmemorar la consolidación de sus relaciones de amistad". El monumento se erigiría recién en $2010^{81}$.

Ese fue el tenor de las conmemoraciones del 7 de junio de ese año, que estuvieron enmarcadas en un simbolismo de paz y fraternidad. Así, se procedió a izar ambas banderas en la cima del Morro en señal de concordia, por orden expresa del Presidente lbáñez del Campo ${ }^{82}$. El hecho era, según editorializó el ahora moderado periódico La Aurora, "el advenimiento definitivo y simbólico de que nada ni nadie podrá quebrantar entre ambas naciones", que gracias a la "varilla mágica de la paz", se unían "en un abrazo fraternal o en una eclosión de emociones comunes" ${ }^{83}$. El medio tacneño El Pacífico, por su parte, alabó la iniciativa por el simbolismo que entrañaba: "Llegó la hora de desarmar los espíritus, de abandonar la hosca hostilidad, de suavizar la mueca huraña. Llegó la paz, la verdadera paz; la compenetración de las mentes, la comunidad de los intereses, la unificación de los destinos" ${ }^{84}$

Las prácticas y discursos de la ceremonia se ciñeron al simbolismo. Así, las festividades al interior de las escuelas siguieron, a diferencia de años anteriores, ese espíritu de conciliación. Se representaron alegorías a ambas banderas y se ofrecieron a los estudiantes conferencias, "que pusieron en alto relieve los valores morales de ambos pueblos". En las ceremonias del Morro, lideradas por el gobernador, el coronel Rafael Pizarro, la conmemoración abandonó el sentido de exaltación nacionalista habitual. De hecho, en el discurso pronunciado en la ocasión por el teniente A. Harnecker afirmó que la paz era "el mayor triunfo de toda la campaña". Y añadía: "Grandes han sido los sufrimientos y horrores de la guerra, no tratemos de alimentar en nuestro corazón ideas rencorosas que abran las heridas que no han cicatrizado por completo y llevemos nuestros sentimientos hacia un punto de más nobles demostraciones. Los rencores,

\footnotetext{
81 En noviembre de 1933 se procedió a la redacción del protocolo del monumento, que "consistirá en una estatua enhiesta del Salvador del Mundo en actitud de predicar su doctrina de paz y amor. La estatua será vaciada en bronce, conforme al modelo que aprobarán previamente ambos Gobiernos y colocada sobre una escalinata de granito y un pedestal, en el sitio adecuado más prominente del Morro de Arica, de modo que pueda ser claramente vista desde tres millas antes de entrar al puerto por las naves que se dirijan a él". Novak, Fabián. 2000. Las conversaciones entre Perú y Chile para la ejecución del Tratado de 1929, Lima, Pontificia Universidad Católica del Perú, p. 175. Solo en marzo de 2010 se levantó en la cima del Morro el Cristo de la Concordia.

82 "Mañana, 7 de junio, flamearán juntos sobre el morro los pabellones de Chile y del Perú", La Aurora, 6 de junio de 1929.

83 "Las dos banderas", La Aurora, 6 de junio de 1929.

84 "Bello gesto", El Pacífico, 6 de junio de 1929.
} 
mantenidos por sobre los límites que el tiempo les designa a nada conducen y a nada engendran" 85 .

\section{Reflexiones finales}

Con frecuencia el pasado es un campo social e ideológico de batallas por monopolizar e imponer su sentido. Un mismo suceso histórico es objeto de controversias sobre su interpretación, sobre los discursos que encierra y los usos políticos de los que es susceptible. El pasado, en ese registro, resulta maleable, sirviendo para propósitos de legitimación, reivindicación, identificación o ruptura, de acuerdo con los intereses funcionales del presente ${ }^{86}$. El pasado reciente, especialmente cuando este remite a sucesos tan dramáticos como la guerra, profundiza esta dimensión polémica. Como lo refleja la investigación aquí expuesta, una batalla como la librada en el Morro de Arica el 7 de junio de 1880 fue conceptualizada de manera disímil por las comunidades peruanas y chilenas de la ciudad, para servir a propósitos ideológicos e identitarios diferentes. Los rituales conmemorativos, en tanto prácticas sociales que explícitamente se proponen rescatar hitos históricos del olvido y fijar el sentido de su recuerdo en las comunidades participantes en sus dinámicas de interacción, fueron la caja de resonancia de estas disputas.

El estado de indefinición jurídica de Arica, ocupada por Chile desde 1880, pero cuyo estatuto de soberanía se mantuvo ambiguo hasta la firma del tratado de 1929, incidió decisivamente en este tipo de controversias. La reivindicación de la peruanidad o la exaltación del nacionalismo belicista chileno se dieron en este marco de proyectos de nacionalización de la frontera, escenario donde los usos de la Guerra del Pacífico para los discursos patrióticos de la época se acentuaron. En el caso chileno, las conmemoraciones de la batalla de Arica sirvieron para escenificar y ensalzar ritualmente a la guerra como su condición de incorporación al Estado chileno. En paralelo, este proceso iba de la mano con la violenta negación - tanto simbólica como en los hechos - del pasado peruano de la ciudad. Durante casi medio siglo, la Guerra del Pacífico y los imaginarios forjados en su desarrollo se recrearon, actualizaron y se prolongaron en el tiempo, incluso en nuevas generaciones que, de manera vicaria, eran compulsivamente expuestas a narrativas belicistas. Así, este tipo de festividades cívicas, con su serie de discursos y prácticas, conjuraban periódicamente la presencia de Marte, el dios de la guerra, que volvía anualmente a proyectar sus sombras en el Morro.

\footnotetext{
85 "Con toda solemnidad se izaron ayer en el Morro los pabellones de Chile y del Perú", La Aurora, 8 de junio de 1929 ${ }^{86} \mathrm{Hartog}$, François y Revel, Jacques. 2001. Les usages politiques du passé, París, Editions de L'École des Hautes Études en Sciences Sociales, p. 14.
} 


\section{Referencias citadas}

Aguilera, René. 2017. "La cuestión eclesial de Tacna y Arica: religión, paradiplomacia y frontera (19001911)", en Aldea Mundo, N 44, Táchira, pp. 91-70.

Aguirre, Claudio y Mondaca, Carlos. 2011. "Estado nacional y comunidad andina. Disciplinamiento y articulación social en Arica, 1880-1929”, en Historia, Vol.44, №1, Santiago, pp. 5-50.

Barrios, Marbert. 2006. “Arica y Tacna: Ciudadanía en tiempos de conflicto (1880-1929)”, en Diálogo Andino, № 28, Arica, pp. 63-80.

Basadre, Jorge. 1974 "Los conflictos de pasiones y de intereses en Tacna y Arica (1922-1929)", en Historia y Cultura, $\mathrm{N}^{\circ} 8$, Lima, pp. 1-68.

Castro, Luis. 2014. "Imaginarios y chilenización: los agentes fiscales chilenos y su visión del espacio y la población andina de la provincia de Tarapacá, norte de Chile 1880-1918", en Anuario de Estudios Americanos, Vol. 71, N², Sevilla, pp. 661-690.

Cid, Gabriel. 2013. "Nacionalizando memorias periféricas: conmemoraciones y nacionalismo chileno en las regiones de Antofagasta y Tarapacá, 1879-1910", en História Unisinos, Vol. 17, №3, São Leopoldo, pp. 214-225.

Cid, Gabriel. 2015. "De guerras, ritos y conquistas: conmemoraciones bélicas y nacionalismo chileno en el «norte grande», 1879-1910", en Cavieres, Eduardo y Chaupis, José (eds.). La Guerra del Pacífico en perspectiva histórica. Reflexiones y proyecciones en pasado y en presente, Santiago, Universidad de Tarapacá, pp. 185-202.

Confino, Alon. 1997. "Collective Memory and Cultural History: Problems of Method", en The American Historical Review, Vol. 102, N², Chicago, p. 1391.

Cubas, Ricardo. 2018. “El presbítero Juan Vitaliano Berroa frente a la chilenización de Tacna y Arica (19041926): un caso de resistencia civil”, en Ibarra, Patricio y Morong, Germán (eds.). Relecturas de la Guerra del Pacífico: avances y perspectivas, Santiago, Ediciones Universidad Bernardo O’Higgins, pp. 215-254.

Díaz Aguad, Alfonso y Pizarro, Elías. 2004. "Tacna y Arica en tiempos del Centenario”, en Diálogo Andino, $\mathrm{N}^{\circ} 24$, Arica, pp. 29-38.

Díaz, Alberto, Ruz, Rodrigo y Galdames, Luis (comp.). 2014. Tiempos violentos. Fragmentos de historia social en Arica, Iquique, Ediciones Universidad de Tarapacá.

Díaz, Alberto (et. al.). 2012. "Nación y ritualidad en el desierto chileno. Representaciones y discursos nacionales en Iquique (1900-1930)", en Polis, Vol. 11, N 31, Santiago, pp. 373-389.

Ferreira, Elizabeth y Aranda, Gilberto. 2019. "Ciudad de papel Zig-Zag. Chilenizando la frontera norte, Arica 1910-1930", en Cuadernos de Historia, N50, Santiago, pp. 9-42.

Figueroa, Carolina y Silva, Benjamín. 2006. "Entre el caos y el olvido. La acción docente en la Provincia de Tarapacá-Chile (1880-1930)", en Cuadernos Interculturales, Vol. 4, №6, Viña del Mar, pp. 37-53.

Galdames, Luis, Ruz, Rodrigo y Díaz, Alberto. 2018. Imaginarios nacionales de la frontera norte chilena. Revistas magazinescas (1883-1930), Iquique, Universidad de Tarapacá. 
Gálvez, Carlos. 2015. "Francisco Bolognesi o la construcción del héroe”, en Novoa, Mauricio (ed.). Bolognesi, Lima, Ministerio de Defensa / Ejército del Perú, pp. 140-155.

García, Juan Carlos. 2000. "El monumento a Benjamín Vicuña Mackenna en Arica", en Anuario del Instituto de Conmemoración Histórica de Chile, N 5, Santiago, pp. 57-60.

Gillis, J. R. ed. 1994. Commemorations: The Politics of National Identity, Princeton, Princeton University Press.

González M., Sergio. 2002. Chilenizando a Tunupa. La escuela pública en el Tarapacá andino 1800-1990, Santiago, DIBAM/ Lom.

González M., Sergio. 2004. El dios cautivo. Las Ligas Patrióticas en la chilenización compulsiva de Tarapacá (1910-1922), Santiago, Lom.

González M., Sergio. 2008. La llave y el candado. El conflicto entre Perú y Chile por Tacna y Arica (18831929), Santiago, Lom/Universidad de Santiago.

González M., Sergio. 2009. “El Norte Grande de Chile: la definición histórica de sus límites, zonas y líneas de fronteras, y la importancia de las ciudades como geosímbolos fronterizos", en Revista de Historia Social y de las Mentalidades, Vol. 13, N², Santiago, pp.9-42.

González P., José. 2010. “La Provincia de Antofagasta. Creación y consolidación de un territorio nuevo en el Estado chileno: 1883-1933", en Revista de Indias, Vol. 70, № 249, Madrid, pp. 345-380.

Hartog, François y Revel, Jacques. 2001. Les usages politiques du passé, París, Editions de L'École des Hautes Études en Sciences Sociales.

Ihl, Olivier. 2002. "La monumentalisation de la voi publique. Sur les politiques d'attribution des noms de rue aux XIX et XXe siècles", en Poirrier, Philippe (dir.), Les collectivités locales et la culture, París, La Documentation Française /Comité d'Histoire du Ministère de la Culture, pp. 127-144.

Mondaca, Carlos, Gajardo, Yeliza y Sánchez, Elizabeth. 2017. “Celebrando las fiestas patrias chilenas entre peruanos. Escuela, nacionalismo y ritos cívicos en la frontera norte de Chile (Arica y Tacna, 1890-1929)", en Revista Dilemas Contemporáneos, Vol. 4, №3, Toluca, pp. 1-24.

Monteverde, Rodolfo. 2017. "Política internacional de la posguerra del Pacífico, remodelación urbana y proyectos escultóricos de Lima: el monumento público a Francisco Bolognesi y los caídos en la batalla de Arica", en Historia, N 50, Vol. II, Santiago, pp. 663-697.

Morong, Germán, 2014. "De la historiografía nacional a la historia de los bordes. Violencia epistémica y emergencia de lo subalterno en el contexto de la chilenización del Norte Grande; siglos XIX-XX", en Díaz, Alberto, Ruz, Rodrigo y Galdames, Luis (comp.) Tiempos violentos. Fragmentos de historia social en Arica, Iquique, Ediciones Universidad de Tarapacá, pp. 11-22.

Novak, Fabián. 2000. Las conversaciones entre Perú y Chile para la ejecución del Tratado de 1929, Lima, Pontificia Universidad Católica del Perú.

Ortemberg, Pablo. 2016. "Los centenarios de 1921 y 1924, desde Lima hacia el mundo: ciudad capital, experiencias compartidas y política regional", en Loayza, Alex (ed.), La independencia peruana como representación. Historiografía, conmemoración y escultura pública, Lima, Instituto de Estudios Peruanos, pp. 135-165. 
Pizarro, Elías y Soto Lara, José, 2020. "La institución del Estado Chileno en el sur peruano: Tacna y Arica, 1880-1929”, en Ayer, Vol. 119, №3, Madrid, pp. 75-107.

Pizarro, Elías. 2017. Tránsitos historiográficos. Arica y su hinterland (siglos XVI-XX), Iquique, Ediciones Universidad de Tarapacá.

Skuban, William. 2007. Lines in the Sand. Nationalism and Identity on the Peruvian-Chilean Frontier, Albuquerque, University of New Mexico Press.

Smith, Anthony. 2004. Nacionalismo: teoría, ideología, historia, Madrid, Alianza.

Soto Lara, José y Chávez, Pablo. 2016. "El nacionalismo de la Sociedad de Instrucción Popular de Arica (1914-1925)", en Cuadernos Chilenos de Historia de la Educación, № 5, Santiago, pp. 21-46.

Soto Lara, José. 2013. "La Federación Obrera de Chile (FOCH) como movimiento popular nacionalista en Arica (1920)", en Tradición y Saber, Vol. 10, № 2, Santiago, pp. 65-84.

Valdebenito, Felipe y Lube, Menara. 2014. "Las fronteras de la modernidad. El espacio Tacnoariqueño y la nacionalización del Norte Grande chileno (1883-1929)", en Estudos Ibero-Americanos, Vol. 40, N 2, Porto Alegre, pp. 277-303.

Vicuña, Manuel. 2003. Hombres de palabras. Oradores, tribunos y predicadores, Santiago, Sudamericana / Centro de Investigaciones Diego Barros Arana.

Villarreal, Luis. E. 1926. Gloria al 7 de junio: himno guerrero, recuerdo del plebiscito, Santiago, Casa Amarilla.

Wertsch, James V. 2008. "The narrative organization of collective memory", en Ethos, Vol. 36, N 1, New Jersey, pp. 120-135. 